\title{
Estudo qualitativo fotoelástico do sistema de forças gerado pela mola "T" de retração com diferentes pré-ativações
}

\author{
Luiz Guilherme Martins Maia*, Vanderlei Luiz Gomes**, Ary dos Santos-Pinto***, \\ Itamar Lopes Júnior ${ }^{\star \star \star \star}$, Luiz Gonzaga Gandini Jr. ${ }^{\star \star \star \star \star}$
}

\section{Resumo}

Objetivo: avaliar o sistema de forças gerado pela mola $\mathrm{T}$ utilizada para fechamento de espaços. Métodos: por meio do método experimental fotoelástico, avaliou-se a mola $\mathrm{T}$ utilizada no fechamento de espaços com duas variações de pré-ativação em sua porção apical, sendo uma com $30^{\circ}$ e a outra com $45^{\circ}$. As molas foram confeccionadas com fio retangular de titânio-molibdênio (TMA) de secção 0,017 ” x 0,025", centralizadas no espaço interbraquetes de $27 \mathrm{~mm}$ e ativadas em 5,0mm, 2,5mm e posição neutra. Para melhor confiabilidade dos resultados, os testes foram repetidos em três modelos fotoelásticos igualmente reproduzidos e confeccionados pelo mesmo operador. Para compreensão dos resultados, as franjas fotoelásticas visualizadas no polariscópio foram fotografadas e analisadas qualitativamente. Resultados: por meio da análise qualitativa da ordem de franjas no modelo fotoelástico, notou-se que, nas extremidades de retração e ancoragem, a mola $\mathrm{T}$ com $30^{\circ}$ de ativação apical apresentou um acúmulo de energia discretamente maior para o sistema de forças liberado.

Palavras-chave: Fechamento de espaço ortodôntico. Mola T. Estudo fotoelástico. Retração.

\section{INTRODUÇÃO}

A filosofia extracionista defendida por Tweed na década de 40 levantou uma nova perspectiva para o tratamento ortodôntico, gerando o interesse dos ortodontistas pela mecânica de retração. A partir daí, surgiram vários dispositivos mecânicos para esse propósito e o conhecimento sobre o sistema de forças gerado por cada um deles tornouse um foco constante de pesquisas ${ }^{16,17}$.
No movimento de retração, é imperativo ao ortodontista conhecer os princípios mecânicos envolvidos nesse sistema, para que o movimento dentário ocorra com o máximo de eficiência e o mínimo de esforço aos tecidos periodontais adjacentes $^{1,12}$. O ideal é que o fechamento de espaço ocorra por movimento de retração resultante dos dispositivos ortodônticos do tipo "alça". Nesse caso, a força se torna previsível por exercer íntima

* Professor da Disciplina de Ortodontia do curso de Odontologia da Universidade Tiradentes/SE. Coordenador do curso de Especialização em Ortodontia da Universidade Tiradentes/SE. Especialista em Ortodontia - EAP/APCD - UNESP - Araraquara. Mestre em Ciências Odontológicas - Ortodontia pela Faculdade de Odontologia de Araraquara - UNESP. Doutorando em Ciências Odontológicas - Ortodontia na Faculdade de Odontologia de Araraquara - UNESP.

** Professor Titular de Prótese Removível e Materiais Odontológicos da Faculdade de Odontologia da Universidade Federal de Uberlândia. Mestre e Doutor em Odontologia pela USP - Ribeirão Preto /SP.

*** Professor Livre Docente/Adjunto da Disciplina de Ortodontia do Departamento de Clínica Infantil da Faculdade de Odontologia de Araraquara - UNESP.

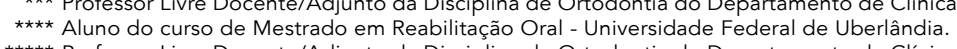

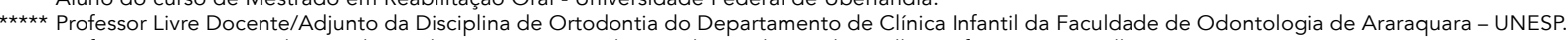
Professor Assistente Adjunto Clínico do Departamento de Ortodontia da "Baylor College of Dentistry - Dallas/TX". 
relação com a dimensão do fio, desenho da alça, tipo de liga, posicionamento da mola, quantidade de ativação, constância das forças, magnitude de força e magnitude do momento $2,3,10,11,13,14,18-21,23,24$.

Já nos dispositivos de retração do tipo "deslizamento", o sistema de forças gerado se torna menos previsivel, uma vez que a magnitude de força é de difícil mensuração, pois parte dela é dissipada pelo atrito durante o movimento ${ }^{1,12}$.

Burstone $^{2}$, em 1982, citou três propriedades que um dispositivo deve exercer durante o movimento de retração: a proporção momento/força, conseguida pela incorporação de dobra do tipo "Gable" e dobras de pré-ativação; a magnitude de força durante as ativações; e a proporção carga/deflexão, representada pela quantidade de energia perdida durante as desativações.

Outra propriedade importante ao plano de tratamento é o tipo de ancoragem que se deseja para a obtenção de uma boa relação dentária ${ }^{2,14}$. Nesse contexto, a eficiência da mola $\mathrm{T}$ idealizada por Burstone e Koenig ${ }^{3}$ agrega várias características ideais para a otimização do fechamento de espaços. As propriedades biomecânicas desse dispositivo já foram alvo de muitos estudos na comunidade ortodôntica e seu sistema de forças é conheci$\mathrm{do}^{2,3,10,11,19-22,24}$ somente com pesquisas utilizando ensaios mecânicos ${ }^{3,10,11,17-24}$ ou elementos finitos ${ }^{13}$. Daí o interesse em avaliar esse sistema por meio do método experimental fotoelástico ${ }^{5-9,15,25}$.

A utilização desse dispositivo na clínica de Pósgraduação em Ortodontia da Faculdade de Odontologia de Araraquara é frequente e se faz presente por meio de constantes pesquisas. O propósito deste trabalho foi avaliar, por meio da fotoelasticida$\mathrm{de}^{5-9,15,25}$, o sistema de forças da mola T centralizada no espaço interbraquetes, utilizando dois tipos de pré-ativações ${ }^{14,20,21}$.

\section{MATERIAL E MÉTODOS}

Inicialmente, foram realizados testes experimentais em 5 modelos-piloto, com a finalidade de permitir a correta investigação da metodologia, selecionar materiais a serem utilizados, definir o número de repetições necessárias, aprimorar a técnica de confecção dos modelos, técnica de leitura e a calibração do pesquisador para obtenção de resultados precisos ${ }^{15}$.

Dois modelos fotoelásticos foram obtidos a partir de um modelo-mestre, construído de fórmica, com as seguintes dimensões: $60 \mathrm{~mm}$ de comprimento, $40 \mathrm{~mm}$ de altura e $20 \mathrm{~mm}$ de espessura (Fig. 1).

Após a obtenção da caixa matriz, utilizou-se dois dentes de acrílico da marca $\mathrm{MOM}^{\circledR}$ (Manequins Odontológicos de Marília, Marília/SP) para serem posicionados e colados nessa caixa matriz. Com o intuito de padronizar o posicionamento desses dentes, foi feito um negativo a partir do modelo-piloto, utilizando borracha de silicona ASB-10 Azul e catalisador para borracha ambos da marca POLIPOX (São Paulo) (Fig. 2), misturados e manipulados seguindo as recomendações do fabricante.

Em seguida, foi confeccionada uma caixa de cera utilidade com as seguintes dimensões: $120 \mathrm{~mm}$ de largura, $140 \mathrm{~mm}$ de comprimento e $90 \mathrm{~mm}$ de altura, para que pudesse ser posicionado o modelo matriz e, posteriormente, despejada a silicona de adição de acordo com a recomendação do fabricante, obtendo-se, assim, o negativo (Fig. 3).

Nessa fase, outros dentes foram posicionados em seus respectivos locais, tomando-se cuidado para que não houvesse contaminação por umidade ou oleosidade na superfície de suas raízes e na silicona. Nesse momento, manipulou-se, em um recipiente de vidro escalonado em mililitros, a resina fotoelástica (marca POLIPOX, CMR-201 Flexível, componente A, código: 584-4, lote: 17680) e o componente endurecedor (CME-252 Flexível, código: 1322-6, lote: 17873) (Fig. 4).

Os dois componentes foram manipulados cuidadosamente durante um período de 10 minutos e, em seguida, verteu-se a mistura no molde obtido anteriormente. Esse molde contendo a resina fotoelástica foi levado à estufa, a uma temperatura constante de $25^{\circ} \mathrm{C}$ durante 24 horas, para completa reação de polimerização da resina (Fig. 5). 


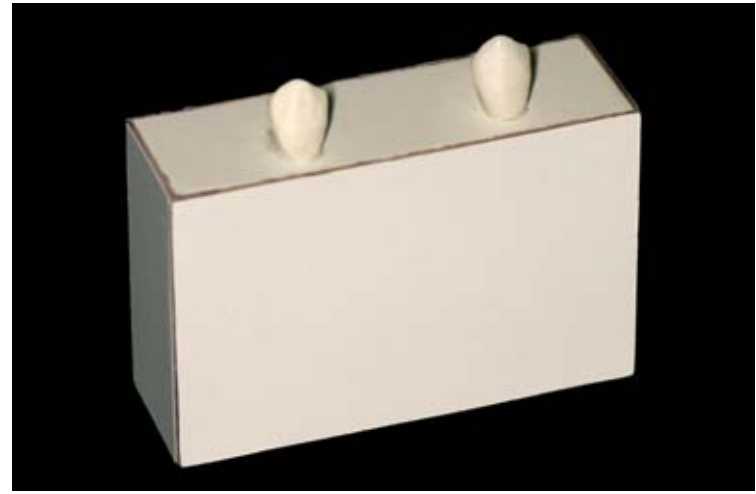

FIGURA 1 - Matriz confeccionada de fórmica para servir de duplicador. Observa-se o posicionamento das coroas dos caninos que serviram de parâmetro para o modelo fotoelástico.
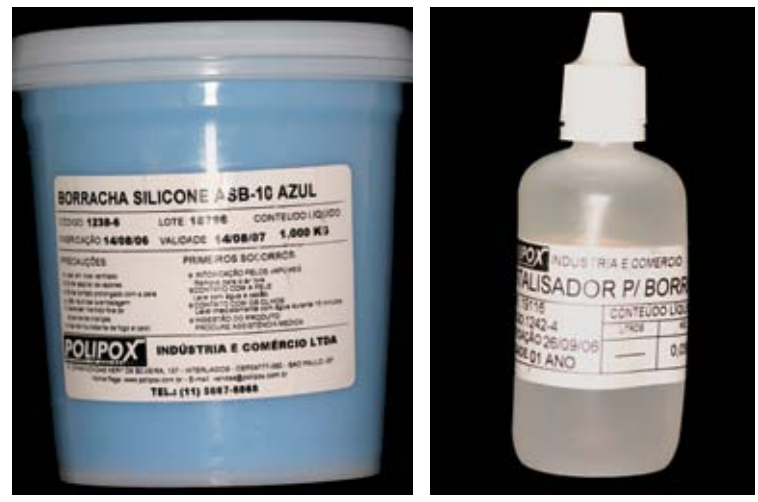

FIGURA 2 - Borracha de silicona e catalisador.
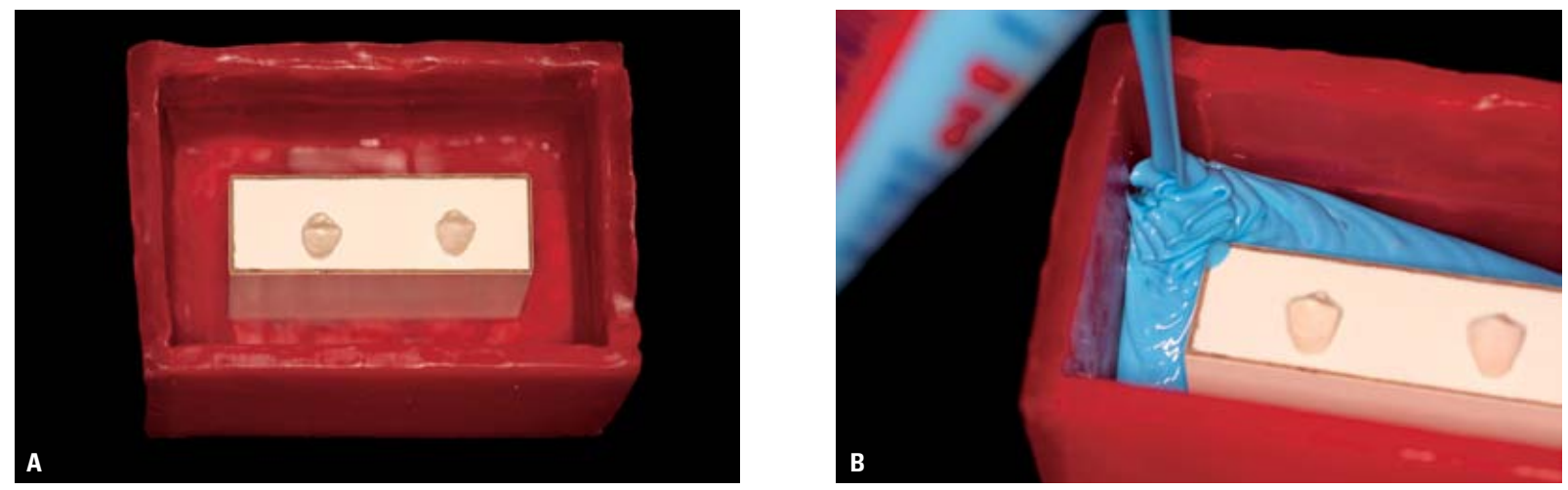

FIGURA 3 - Posicionou-se a matriz dentro da caixa de cera (A) e verteu-se silicona (B) para obtenção do negativo.
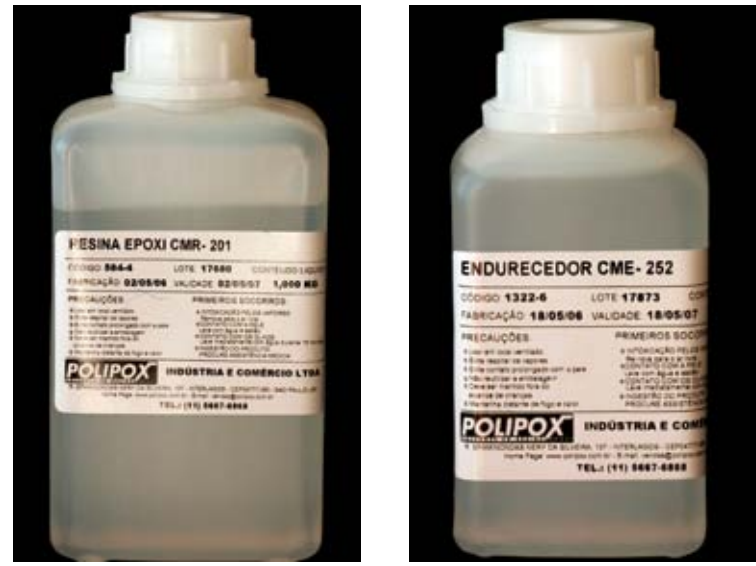

FIGURA 4 - Resina epoxi, componentes A e B.
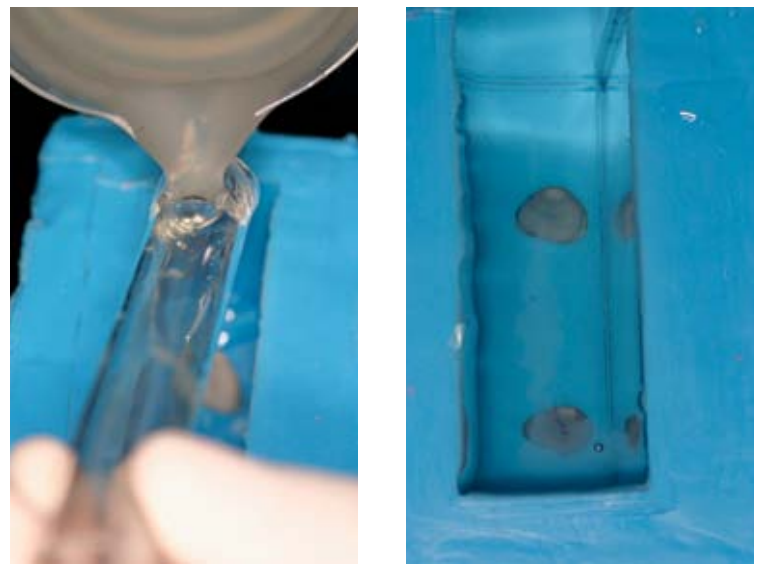

FIGURA 5 - Após a manipulação da resina epoxi, a mesma foi vertida cuidadosamente, para evitar-se a incorporação de bolhas. 
Nessas fases, a resina foi manipulada cuidadosamente para se evitar a incorporação de bolhas de ar.

Decorrido esse tempo, removeu-se o modelo do molde e, nessa fase, foi necessário checar as condições ópticas do modelo fotoelástico no polariscópio. Caso o modelo não apresentasse as propriedades ópticas satisfatórias ${ }^{15}$, o que prejudicaria a análise, era descartado e novamente repetidos os passos até se obter o modelo ideal (Fig. 6).

Com os dois modelos fotoelásticos definidos, fixou-se um tubo cruzado da marca Morelli ${ }^{\circledast}$ (Sorocaba/SP) em cada dente (Fig. 7) e, para isso, foi feita uma canaleta vertical utilizando-se uma broca cilíndrica em baixa rotação, onde os tubos eram encaixados e colados com resina acrílica.

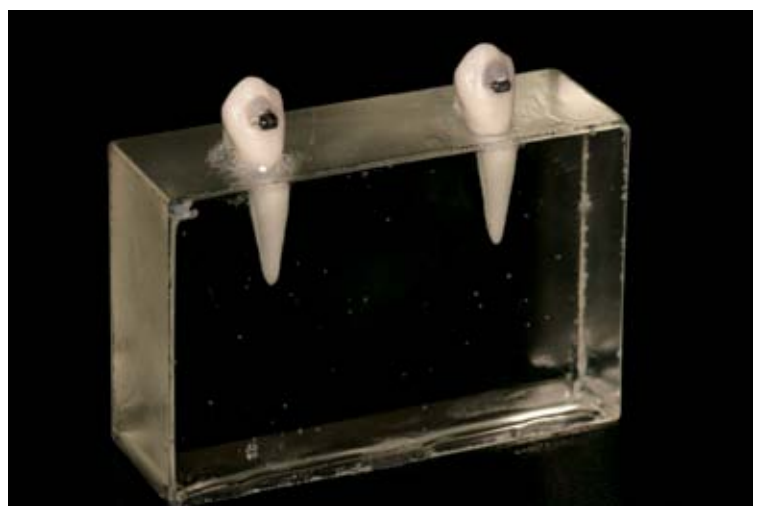

FIGURA 6 - Modelo fotoelástico.

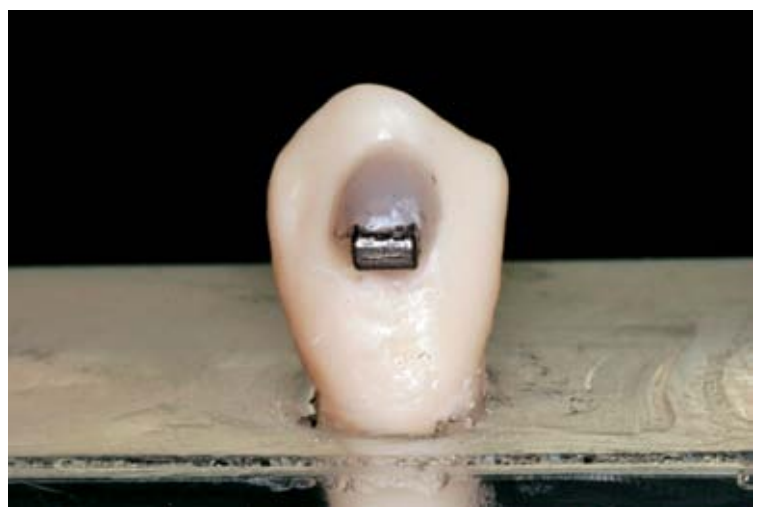

FIGURA 7 - Modelo fotoelástico com os tubos cruzados posicionados.
Para cada modelo, utilizou-se uma mola T, confeccionada com fio de titânio-molibdênio (TMA) de marca Ormco ${ }^{\circledR}$ (Glendora, CA, EUA) com secção transversal de 0,017 " x 0,025 ". No intuito de manter o padrão das molas T, utilizou-se um gabarito com as seguintes dimensões: $10 \mathrm{~mm}$ de comprimento e $7 \mathrm{~mm}$ de altura.

Foram utilizadas duas pré-ativações da base apical, sendo que, para um modelo, foi inserida uma mola $\mathrm{T}$ com pré-ativação na base apical de 45 graus $^{14,21}$ e, para outro modelo, foi inserida uma mola $\mathrm{T}$ com pré-ativação na base apical de 30 graus $^{20}$ (Fig. 8).

Após a checagem em posição neutra das molas $\mathrm{T}$, essas foram inseridas nas canaletas horizontais dos tubos cruzados, centralizadas em uma distância interbraquetes de $27 \mathrm{~mm}^{10}$ e avaliadas em três ativações: $5,0 \mathrm{~mm}, 2,5 \mathrm{~mm}$ e em posição neutra. Para observar a fidelidade dos resultados, esses testes foram repetidos por mais duas vezes e mostraram-se coincidentes.

Os testes foram realizados no laboratório de Engenharia Mecânica da Universidade Federal de Uberlândia/MG (Departamento de Física), avaliados através de um polariscópio de refração e fotografados com equipamento digital Canon Rebel EOS 300D (6,3 megapixels, lente Canon macro $100 \mathrm{~mm}$ Ultrasonic e flash circular Canon Macro Ring Lite MR-14EX) (Fig. 9).

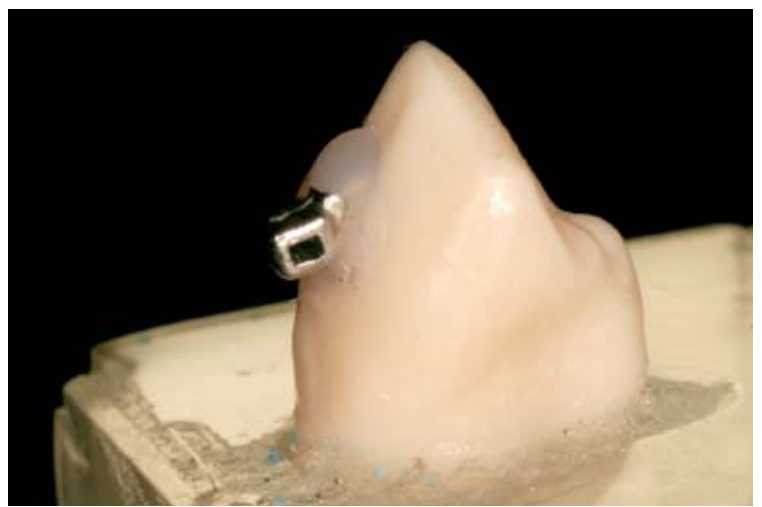




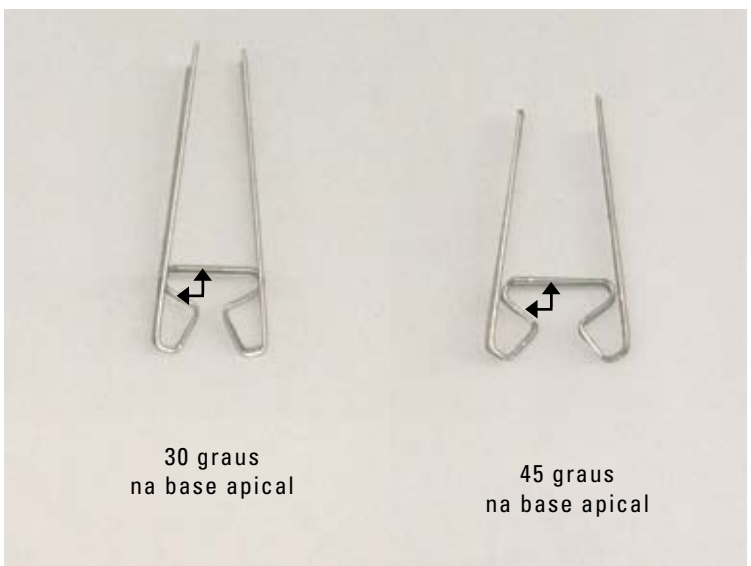

FIGURA 8 - Template para padronizar a confecção das molas T: padrões Souza (30 graus) e Marcotte (45 graus).
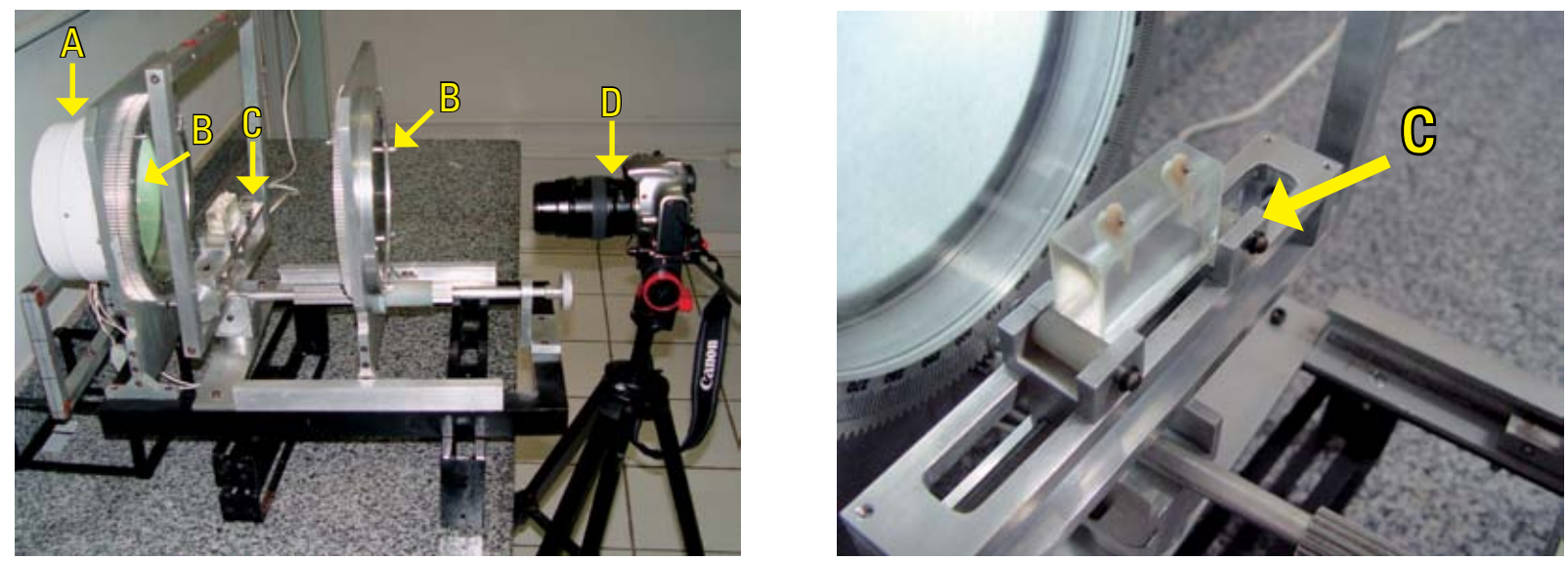

FIGURA 9 - Polariscópio circular plano: A) fonte de luz, B) polarizadores, C) modelo fotoelástico e D) equipamento fotográfico digital.

\section{RESULTADOS}

Os resultados foram obtidos pela leitura das franjas fotoelásticas nos modelos, com a utilização de molas T de Burstone ${ }^{2}$ com dois diferentes tipos de pré-ativação ${ }^{14,20,21}$. A mola foi analisada em três ativações diferentes, sendo a primeira em posição neutra, a segunda com ativação de $2,5 \mathrm{~mm}$ e a última com ativação de $5,0 \mathrm{~mm}$.

As interpretações foram avaliadas de maneira descritiva, sendo as leituras realizadas em gráficos divididos para as três porções de cada dente, sendo uma mesial, uma apical e outra distal, avaliadas uma a uma separada- mente e depois comparadas com o dente adjacente (Fig. 10).

A leitura da ordem das franjas foi realizada através da interface do violeta e azul, formada nas superfícies distal, mesial e apical de cada dente, tomando-se a distância como referência para realizar-se os gráficos de análise. Em uma escala crescente, formam-se as seguintes cores: preto, amarelo, vermelho, azul, amarelo, vermelho, verde, amarelo, vermelho e verde (Fig. 11).

A figura 12 mostra a ordem de franja de 0,0 no modelo fotoelástico, em decorrência da ausência da mola T. Nesse caso, o modelo fotoelástico está 
livre de qualquer interferência de forças.

O gráfico 1 representa um modelo fotoelástico livre de tensão, onde a ordem de franja é de 0,0 em toda a superfície radicular de ambos os dentes.

\section{Ordem de franja e interpretação da mola T com} pré-ativação preconizada por Souza et al. ${ }^{20}$

Em posição neutra, a mola T com pré-ativação preconizada por Souza et al. ${ }^{20}$ demonstrou ordem de franja inferior a 0,5 em toda a superfície radicular. Isso quer dizer que, nessa análise qualitativa, o estresse, apesar de ser distribuído igualmente desde a região cervical até o ápice radicular, sugere pouca quantidade de energia

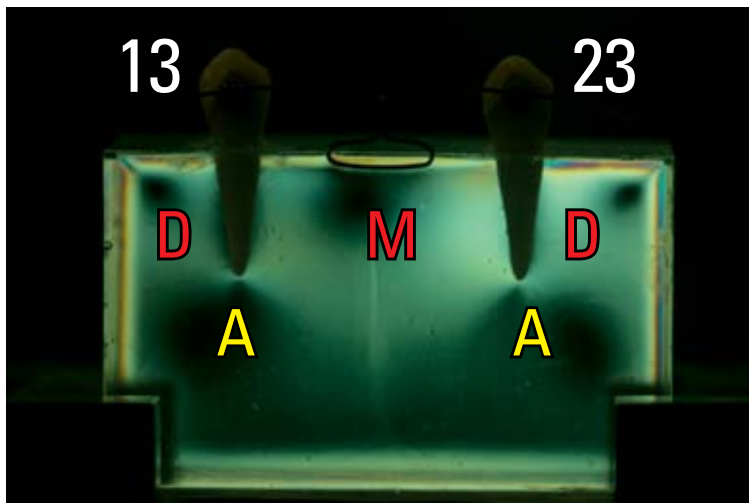

FIGURA 10 - Nomenclatura sugerida para leitura e interpretação da ordem de franja do modelo fotoelástico.

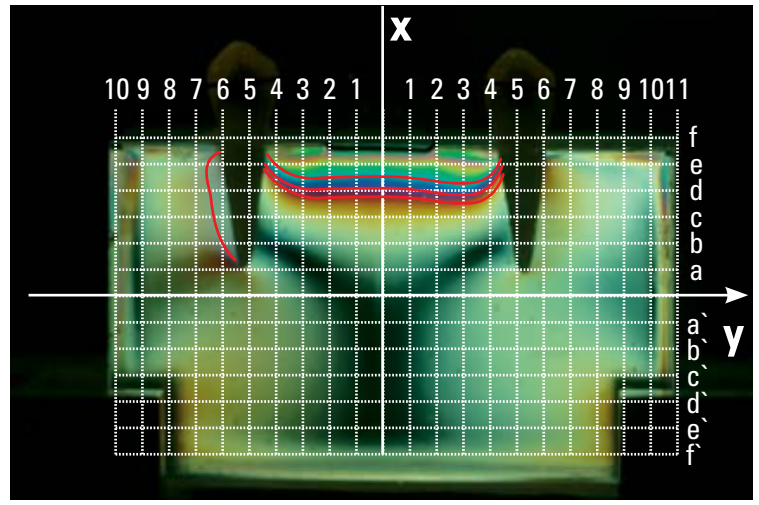

FIGURA 11 - Diagramação do eixo cartesiano para facilitar a leitura dos pontos da ordem de franja no modelo fotoelástico. ou uma magnitude de força muito baixa aplicada nesses dentes (Fig. 13).

A representação no gráfico 2 demonstra que a mola T com pré-ativação de Souza et al. ${ }^{20}$, na posição neutra, formou uma ordem de franja de 0,0 em toda a superfície mesial, com exceção da região cervico-mesial do dente 23 . Nessa região, a ordem de franja foi de 0,0 a 0,5 e não representou relevância.

$\mathrm{O}$ gráfico 3 demonstra que a mola $\mathrm{T}$ com pré-ativação de Souza et al. ${ }^{20}$, na posição neutra, gerou uma ordem de franja de 0,0 em toda a extensão apical para ambos os dentes.

No gráfico 4, verifica-se que a mola T com préativação de Souza et $\mathrm{al}^{2}{ }^{20}$, na posição neutra, exibiu ordem de franja de 0,0 em toda a extensão distal.

Ao analisar a figura 14, observa-se que, nos terços médio e cervical dos dentes 13 e 23 , a ordem de franja apresenta-se entre 1,5 e 2,0. Já na região disto-apical dos dentes 13 e 23, a ordem de franja apresenta-se em 0,5 , considerada com pouca energia gerada para essa região, o que sugere movimento de inclinação controlada. Uma discreta assimetria foi observada na região disto-apical do dente 13 , porém sem relevância significativa para a análise qualitativa, sugestiva de ativação assimétrica ou posicionamento discretamente descentralizado ou, ainda, alguma interferência na confecção da mola.

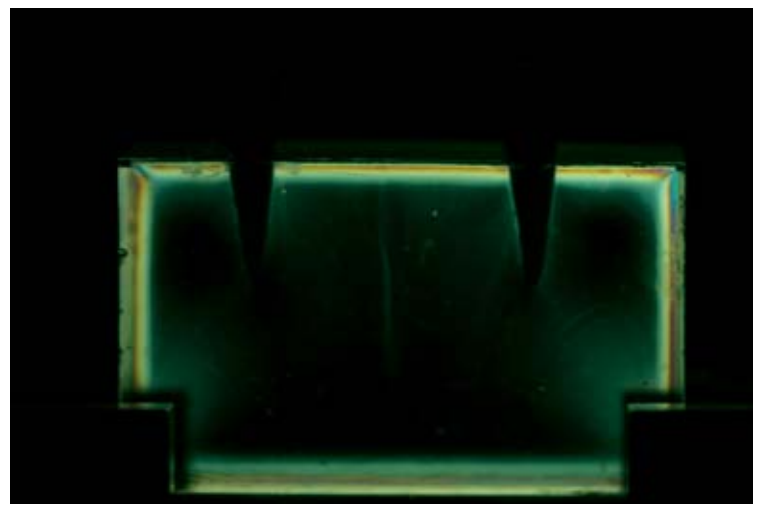

FIGURA 12 - Através do polariscópio, observa-se a ordem de franjas de 0,0 em decorrência da ausência da mola T. 


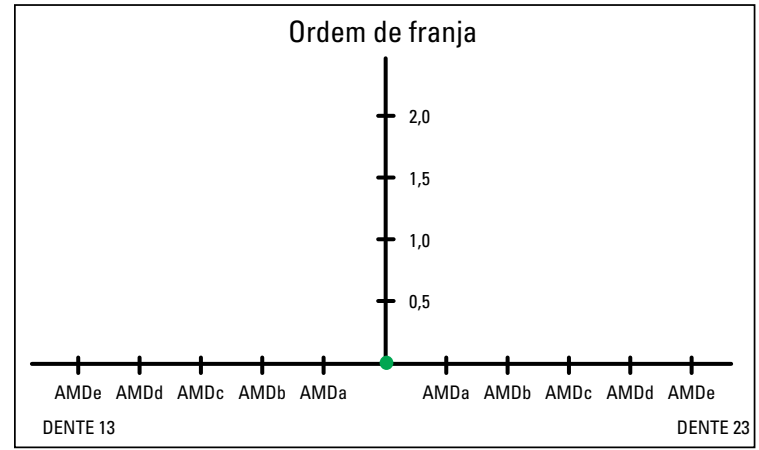

GRÁFICO 1 - 0 ponto verde no vértice do gráfico representa a ordem de franja igual a zero.

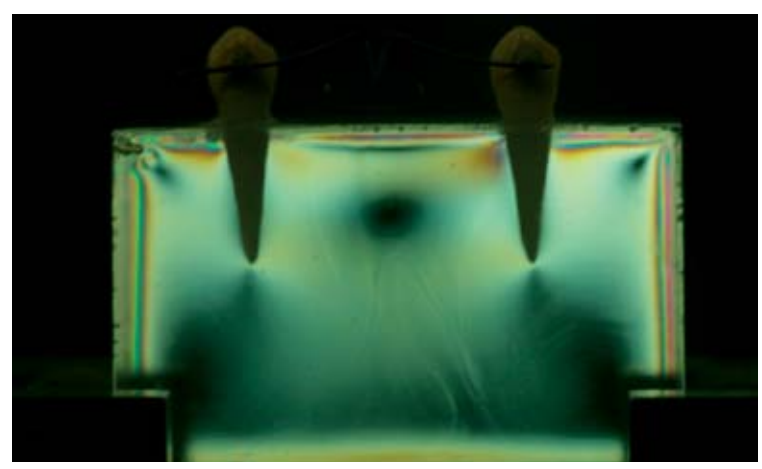

FIGURA 13 - Ativação em posição neutra (ativação de 0,0mm).

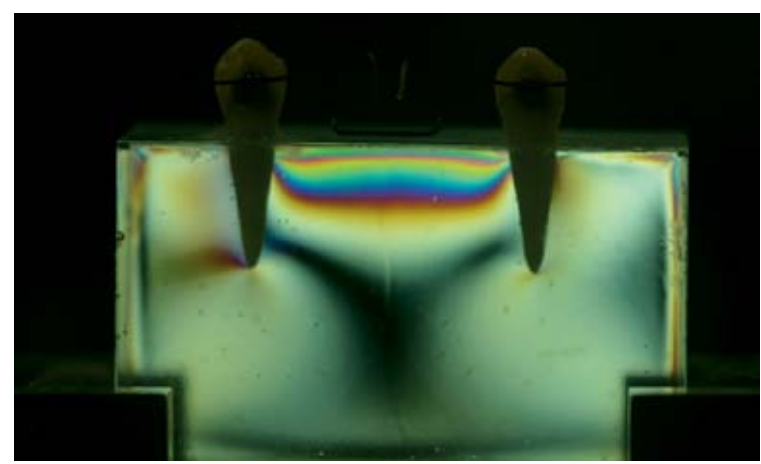

FIGURA 14 - Ativação da mola T em 2,5mm.

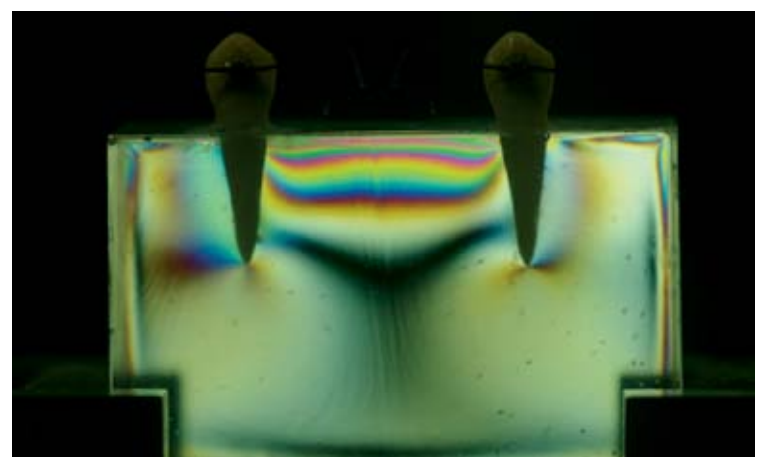

FIGURA 15 - Ativação da mola T em 5,0mm (ativação máxima).

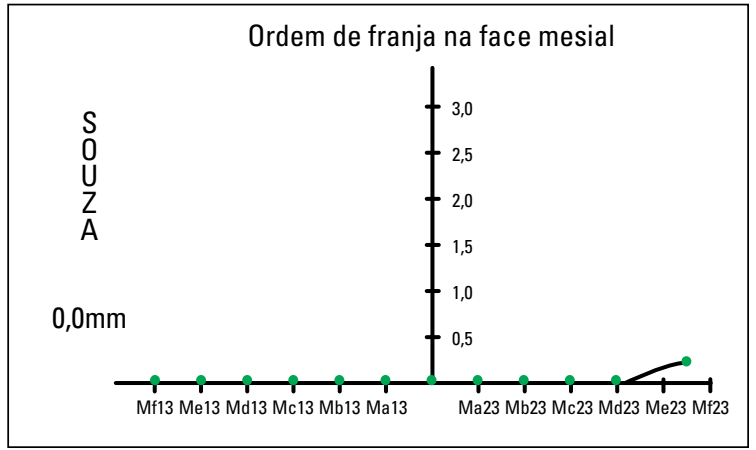

GRÁFICO 2 - Representação da face mesial na pré-ativação de Souza em posição neutra.

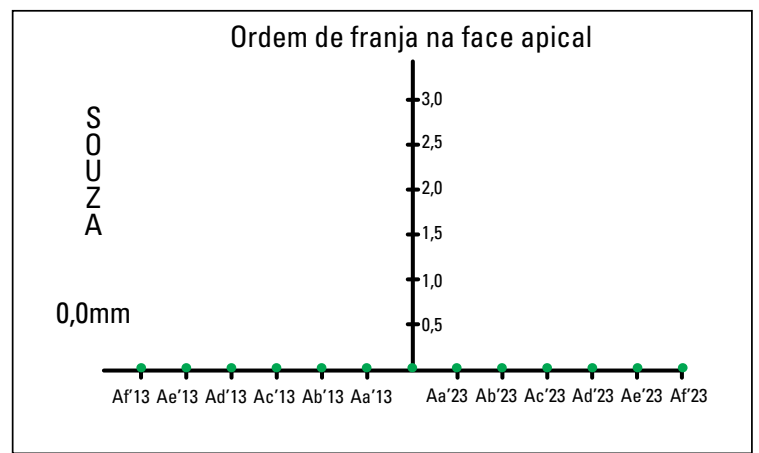

GRÁFICO 3 - Representação da face apical na pré-ativação de Souza em posição neutra.

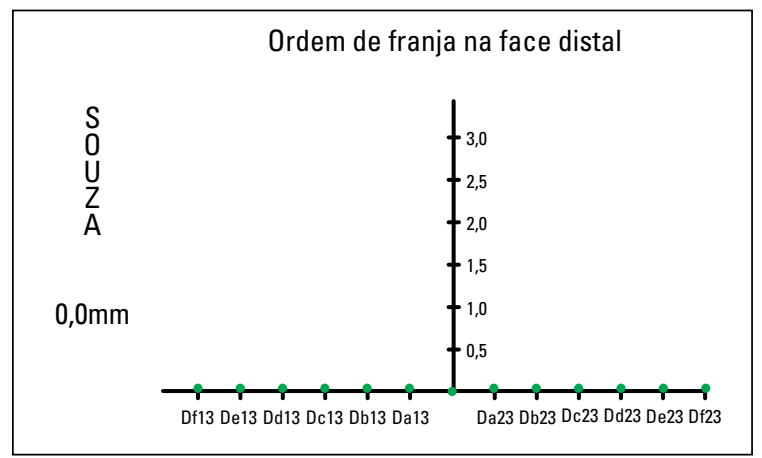

GRÁFICO 4 - Representação da face distal na pré-ativação de Souza em posição neutra.

No gráfico 5 , verifica-se que a mola $\mathrm{T}$ com $2,5 \mathrm{~mm}$ de ativação e pré-ativação preconizada por Souza et al..$^{20}$ exibiu concentração de franjas de 1,5 e propagação dessa ordem de franja de maneira simétrica. 
No gráfico 6, verifica-se que a mola $T$ com $2,5 \mathrm{~mm}$ de ativação e com pré-ativação preconizada por Souza et al. ${ }^{20}$ exibiu uma concentração de franjas próxima de 0,0 , porém discretamente maior para o dente 13 .

No gráfico 7 , verifica-se que a mola $\mathrm{T}$ com $2,5 \mathrm{~mm}$ de ativação e com pré-ativação preconizada por Souza et al. ${ }^{20}$ exibiu uma concentração de franjas de 0,5 no terço disto-cervical do dente 23 e ordem de franja de 0,5 no terço inferior distal do dente 13.

Na figura 15, observa-se ordem de franja discretamente maior que 2,5 , demonstrando que a mola $\mathrm{T}$ com pré-ativação de $30^{\circ}$ apresenta um acúmulo de energia maior em relação à mola $\mathrm{T}$ com pré-ativação de $45^{\circ}$, na mesma ativação.

No gráfico 8 , pode-se verificar que a mola $\mathrm{T}$ com $5,0 \mathrm{~mm}$ de ativação e com pré-ativação preconizada por Souza et al. ${ }^{20}$ exibiu uma concentração de franjas entre 0,5 na região do terço médio radicular e 2,5 na região do terço médio cervical.

No gráfico 9 , verifica-se que a mola $\mathrm{T}$ com $5,0 \mathrm{~mm}$ de ativação e com pré-ativação preconizada por Souza et al. ${ }^{20}$ exibiu uma concentração de franjas entre 0,0 e 0,5 para o dente 23 , e discretamente maior a 0,5 na região apical para o dente 13 .

No gráfico 10 , verifica-se que a mola $\mathrm{T}$ com $5,0 \mathrm{~mm}$ de ativação e com pré-ativação preconizada por Souza et al. ${ }^{20}$ exibiu uma concentração de franjas de 0,5 em toda a superfície distal radicular dos dentes 23 e 13 .

Ordem de franja e interpretação da mola T com pré-ativação preconizada por Marcotte ${ }^{14}$

Em posição neutra, a mola $\mathrm{T}$ com as pré-ativações preconizadas por Marcotte ${ }^{14}$ demonstrou que a ordem de franja foi inferior a 0,5 em toda a superfície radicular. Isso quer dizer que, nessa análise qualitativa, o estresse, apesar de ser distribuído igualmente desde a região cervical até o ápice radicular, sugere pouca quantidade de energia ou magnitude de força baixa aplicada nos dentes (Fig. 16).

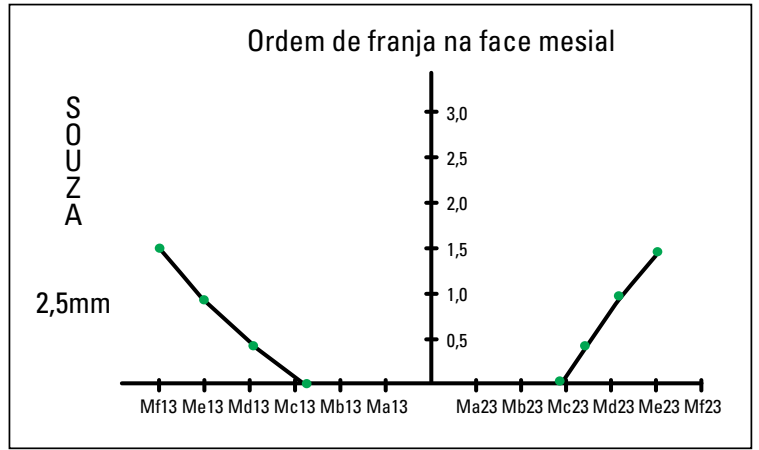

GRÁFICO 5 - Representação da face mesial na pré-ativação de Souza com 2,5mm de ativação.

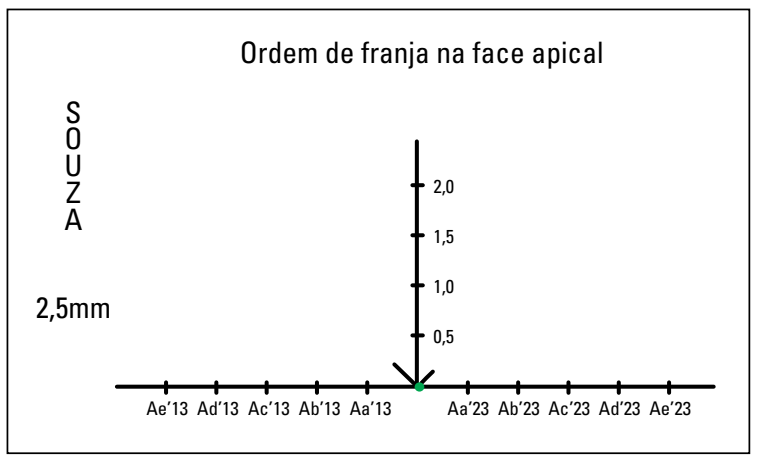

GRÁFICO 6 - Representação da face apical na pré-ativação de Souza com 2,5mm de ativação.

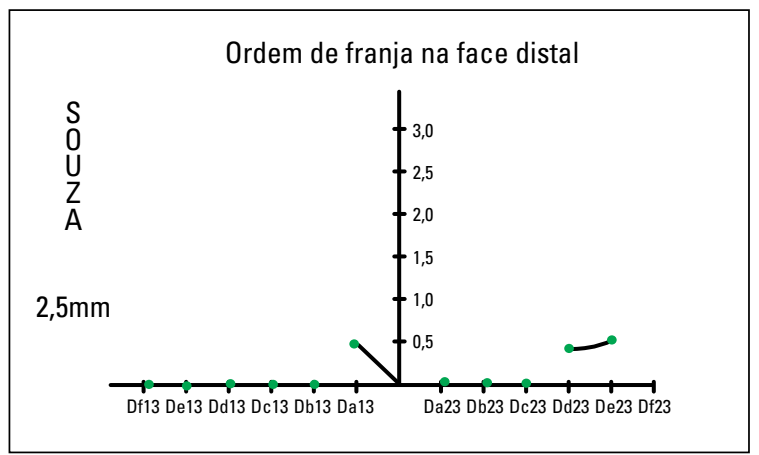

GRÁFICO 7 - Representação da face distal na pré-ativação de Souza com 2,5mm de ativação.

No gráfico 11, verifica-se que a mola T com préativação de Marcotte $^{14}$, na posição neutra, exibiu, em toda a extensão mesial, a ordem de franja de 0,0 .

No gráfico 12 , verifica-se que a mola $\mathrm{T}$ com pré-ativação de Marcotte $^{14}$, na posição neutra, exibiu, em toda a extensão apical, a ordem de 


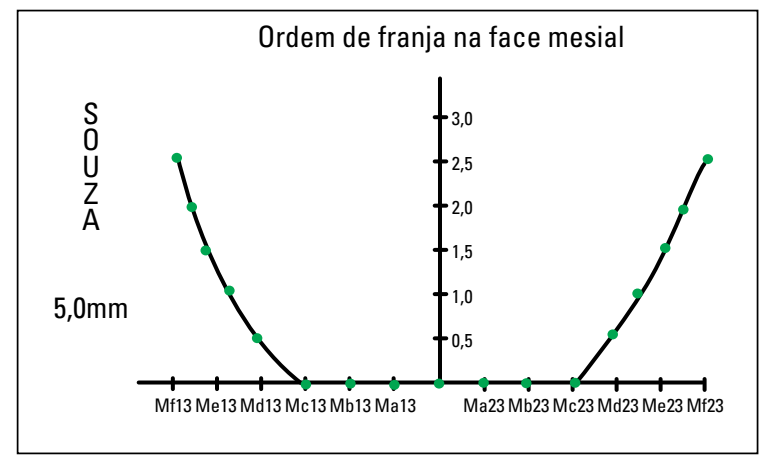

GRÁFICO 8 - Representação da face mesial na pré-ativação de Souza com 5,0mm de ativação.

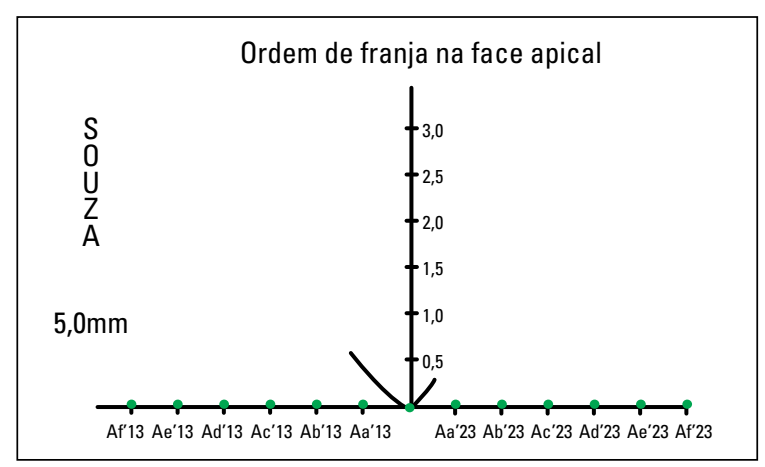

GRÁFICO 9 - Representação da face apical na pré-ativação de Souza com $5,0 \mathrm{~mm}$ de ativação.

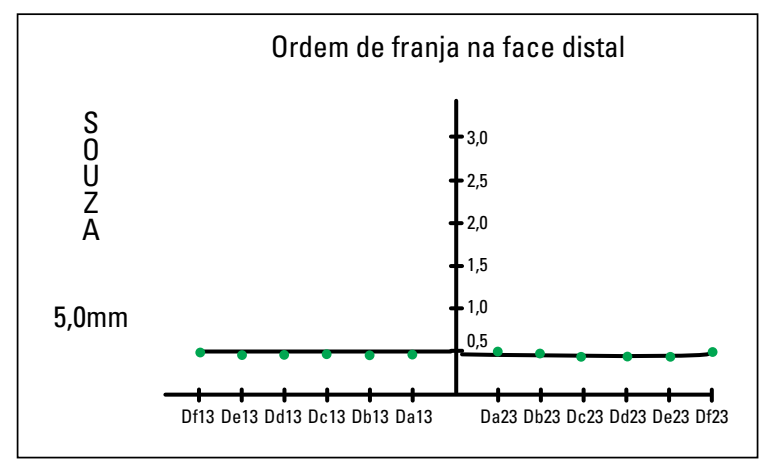

GRÁFICO 10 - Representação da face distal na pré-ativação de Souza com $5,0 \mathrm{~mm}$ de ativação.

franja de 0,0 .

No gráfico 13, na representação gráfica da mola $\mathrm{T}$ com pré-ativação de Marcotte $^{14}$ na posição neutra, observa-se que, em toda a extensão distal, a ordem de franja foi de 0,0 .

$\mathrm{Na}$ figura 17, observa-se ordem de franja discre-

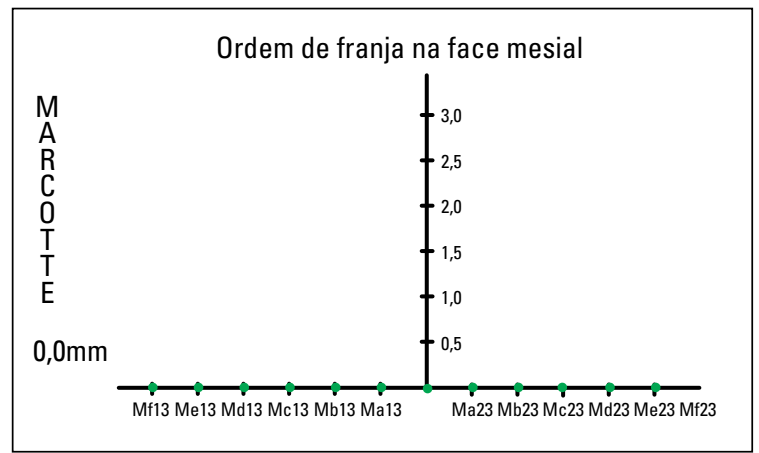

GRÁFICO 11 - Representação da face mesial na pré-ativação de Marcotte em posição neutra.

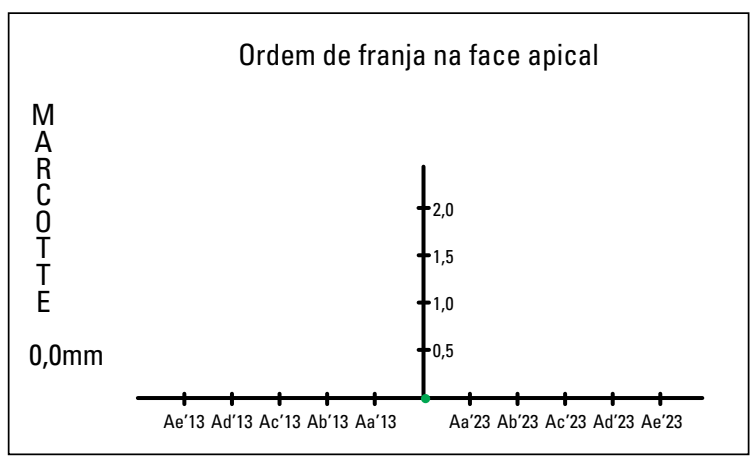

GRÁFICO 12 - Representação da face apical na pré-ativação de Marcotte em posição neutra.

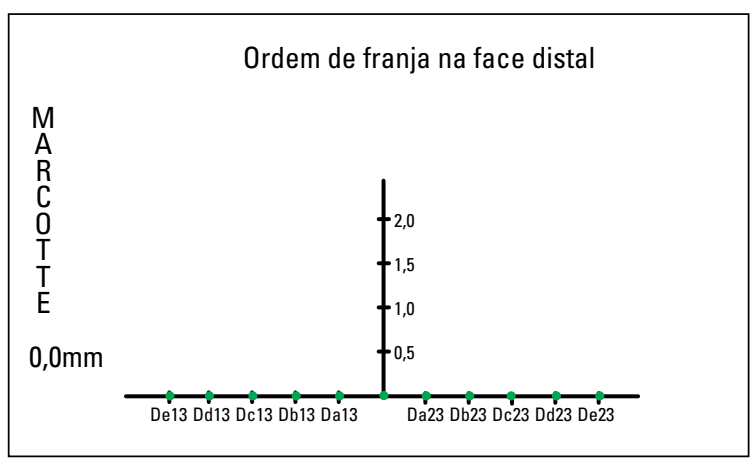

GRÁFICO 13 - Representação da face distal na pré-ativação de Marcotte em posição neutra.

tamente menor que 1,5 , demonstrando que a mola $\mathrm{T}$ com pré-ativação de $45^{\circ}$ apresenta um acúmulo de energia discretamente menor em relação à mola $\mathrm{T}$ com pré-ativação de $30^{\circ}$, quando ativada a $2,5 \mathrm{~mm}$.

No gráfico 14 , verifica-se que a mola T ativada $2,5 \mathrm{~mm}$ e com pré-ativação preconizada por 


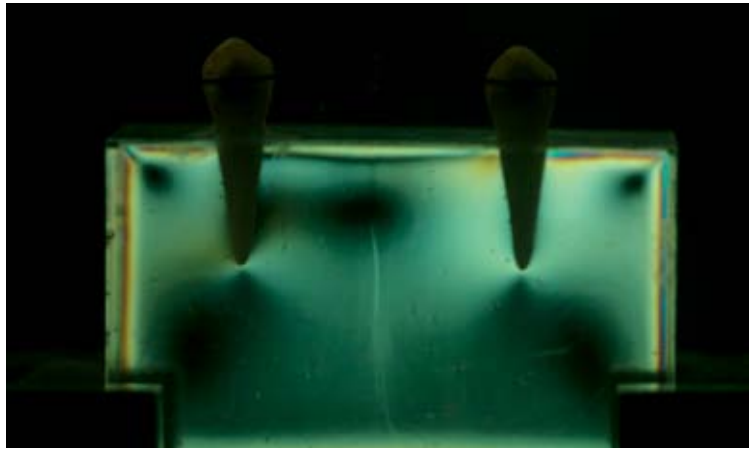

FIGURA 16 - Ativação em posição neutra (ativação de 0,0mm).

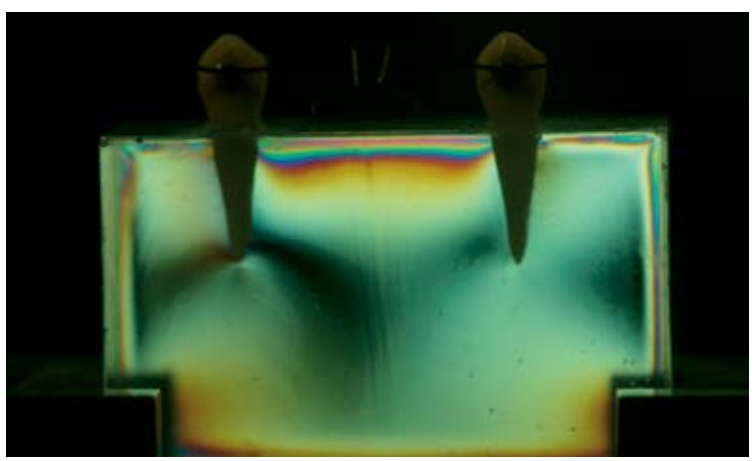

FIGURA 17 - Ativação da mola em 2,5mm.

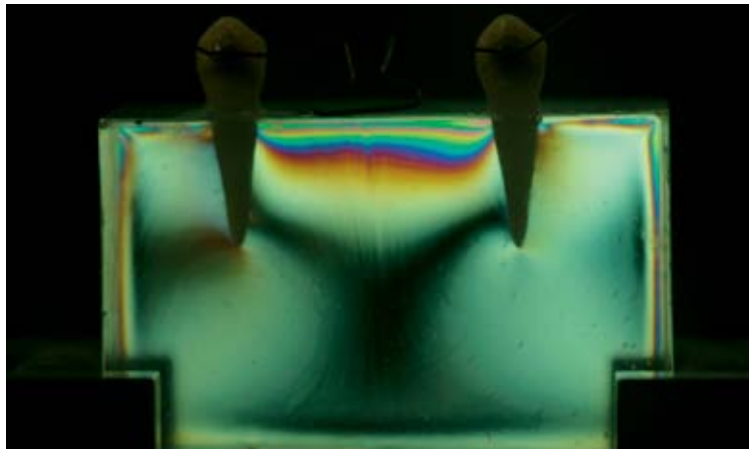

FIGURA 18 - Ativação da mola em 5,0mm.

Marcotte ${ }^{14}$ exibiu concentração de franjas entre 0,0 no terço médio da superfície radicular e 1,5 no terço cervical.

O gráfico 15 demonstra que a mola $\mathrm{T}$ com $2,5 \mathrm{~mm}$ de ativação e com pré-ativação preconizada por Marcotte ${ }^{14}$ gerou uma concentração de franjas próxima a 0,0 no terço apical.

No gráfico 16, verifica-se que a mola $\mathrm{T}$ com pré-ativação de Marcotte $^{14}$, na ativação de $2,5 \mathrm{~mm}$, exibiu, em toda a extensão distal, a ordem de franja de 0,0 .

$\mathrm{Na}$ figura 18, observou-se ordem de franja aquém de 1,5 , o que demonstra que a mola $\mathrm{T}$ com pré-ativação de $45^{\circ}$ apresenta acúmulo de energia discretamente menor em relação à mesma mola com pré-ativação de $30^{\circ}$, quando ativada a $2,5 \mathrm{~mm}$. Ao comparar as figuras 17 e 18, observou-se uma ordem de franja diferente entre as ativações de $2,5 \mathrm{~mm}$ e de $5,0 \mathrm{~mm}$ utilizando-se a pré-ativação preconizada por Marcotte $^{14}$, sendo que houve maior energia para a ativação de $5,0 \mathrm{~mm}$.

No gráfico 17, verifica-se que a mola $T$ com $5,0 \mathrm{~mm}$ de ativação e com pré-ativação preconizada por Marcotte ${ }^{14}$ exibiu uma concentração de franjas entre 0,0 no terço médio e 1,5 no terço cervical. Ao comparar-se com o gráfico 8 , observou-se que a ordem de franja foi mais intensa para a mola $\mathrm{T}$ com pré-ativação preconizada por Souza et al. ${ }^{20}$ ativada a $5,0 \mathrm{~mm}$, demonstrando que a energia gerada por aquela mola é mais alta.

No gráfico 18, verifica-se que a mola $\mathrm{T}$ com 5,0mm de ativação e com pré-ativação preconizada por Marcotte ${ }^{14}$ exibiu uma concentração de franjas entre 0,0 e 0,5 no terço apical, porém houve energia mais alta para o dente 13 .

No gráfico 19, verifica-se que a mola $\mathrm{T}$ com $5,0 \mathrm{~mm}$ de ativação e com pré-ativação preconizada por Marcotte ${ }^{14}$ exibiu uma concentração de franjas próxima de 0,5 na região disto-cervical do dente 23 e uma ordem de franja de 0,5 na superfície distal no terço inferior do dente 13.

Ao analisar cada figura, notou-se que, para ambas as pré-ativações, a concentração de energia desprendida é muito semelhante e acontece de forma simétrica em todos os testes. Observou-se presença de pequena assimetria e acredita-se que essa seja decorrente da discreta descentralização da mola no ato da instalação e/ou em sua ativação ou, ainda, uma assimetria ocorrida em sua confecção. 


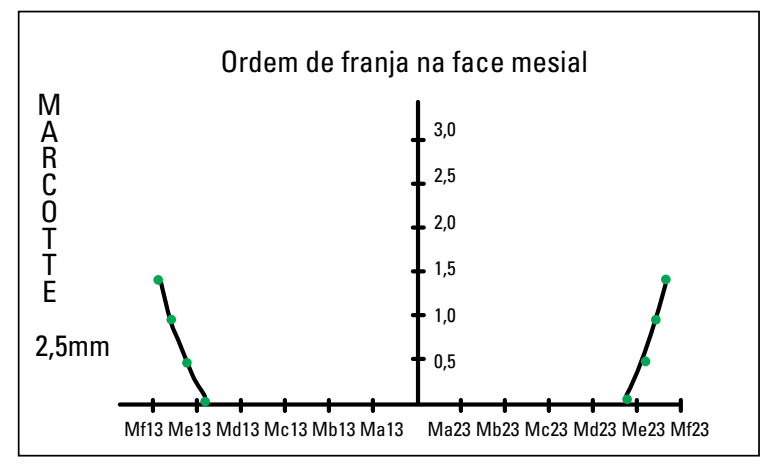

GRÁFICO 14 - Representação da face mesial na pré-ativação de Marcotte com 2,5mm de ativação.

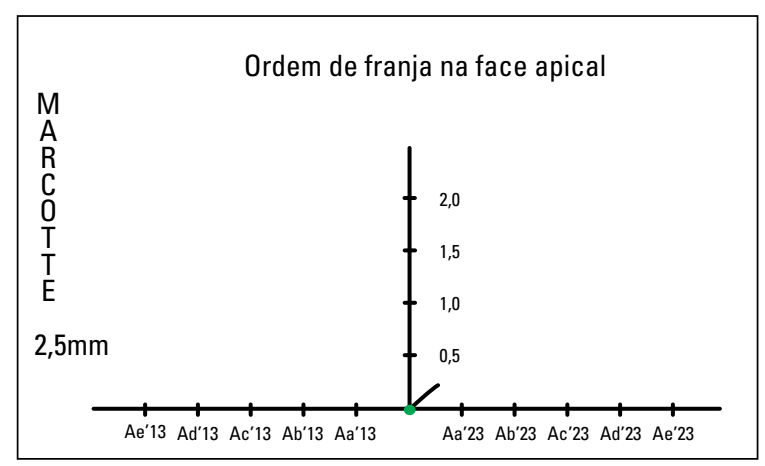

GRÁFICO 15 - Representação da face apical na pré-ativação de Marcotte com 2,5mm de ativação.

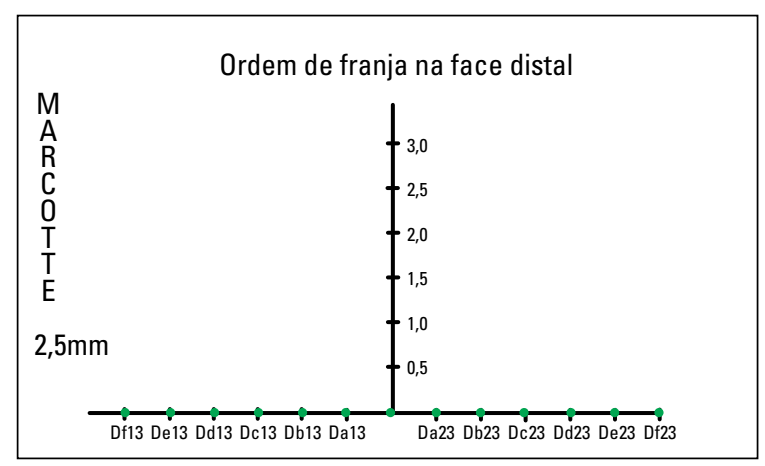

GRÁFICO 16 - Representação da face distal na pré-ativação de Marcotte com 2,5mm de ativação.

\section{DISCUSSÃO}

O fechamento de espaços na Ortodontia deve ser realizado conforme a necessidade apresentada em cada caso específico ${ }^{2,3,4,6,11,13,14,17-24}$. A escolha adequada dos diversos mecanismos requer profundo conhecimento da biomecânica apresentada pe-

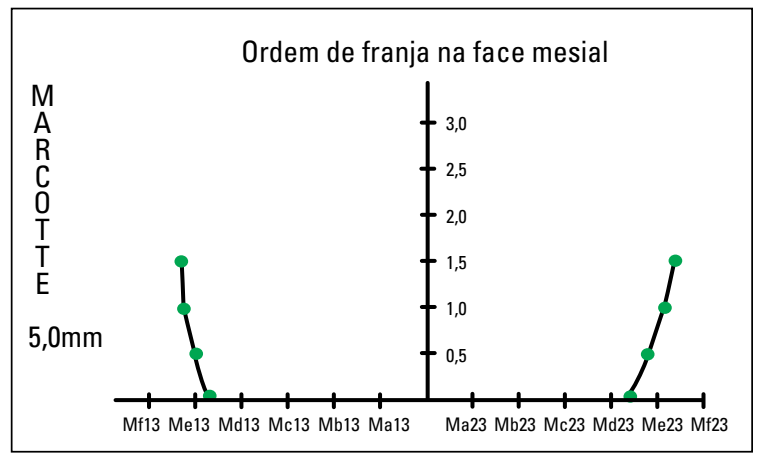

GRÁFICO 17 - Representação da face mesial na pré-ativação de Marcotte com 5,0mm de ativação.

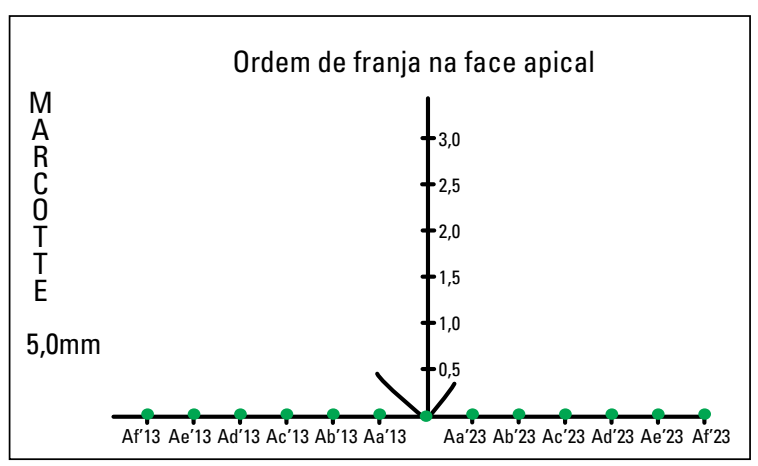

GRÁFICO 18 - Representação da face apical na pré-ativação de Marcotte com 5,0mm de ativação.

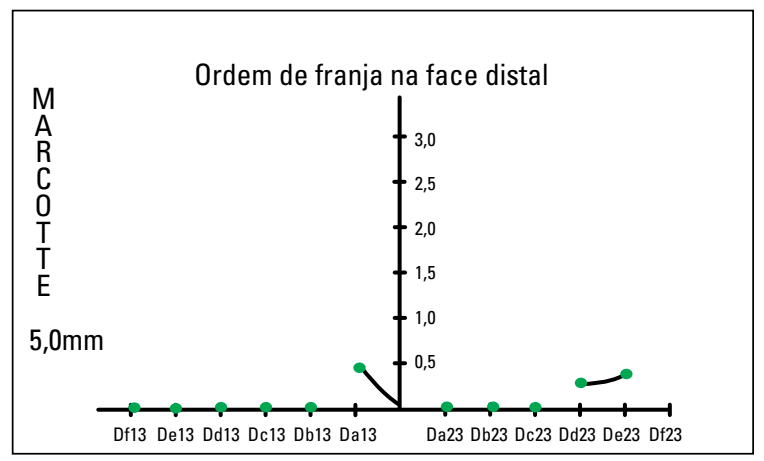

GRÁFICO 19 - Representação da face distal na pré-ativação de Marcotte com 5,0mm de ativação.

los dispositivos de retração, assim como o sistema de forças liberado por eles. Para isso, as molas de fechamento de espaço deverão liberar uma baixa proporção carga/deflexão e uma alta proporção momento/força, possibilitando, desse modo, um bom controle do movimento dentário. 
O objetivo deste trabalho foi avaliar, pelo método experimental fotoelástico, o sistema de forças da mola T centralizada com dois tipos de pré-ativação, de 30 graus $^{20}$ e de 45 graus $^{14,21}$.

O fenômeno fotoelástico foi introduzido em 1935 por um ortodontista ${ }^{25}$ que, em sua pesquisa utilizando dentes esculpidos à base de resina com propriedade fotoelástica, avaliou as áreas de pressão e tensão nas suas raízes quando forças eram aplicadas. A partir daí, a fotoelasticidade tomou seu lugar permanentemente nas pesquisas para avaliar as propriedades de materiais odontológicos que sofrem, de alguma forma, certo tipo de força intrabucal $^{6,8,9,15}$. Ela se baseia no fato de um material transparente ser opticamente ativo sob situações de carga quando iluminado por luz monocromática. Dessa forma, linhas escuras e claras intercalam-se, formando o que se denomina de linhas isocromáticas e isoclínicas. Esse efeito óptico, denominado franja fotoelástica, traduz a tensão ou deformação sofrida pelo corpo, podendo ser mensurado tanto qualitativa como quantitativamente ${ }^{9}$.

Esse método avalia a situação inicial de tensão, limitando-se apenas à fase inicial do movimento dentário ${ }^{13}$, registrado por um equipamento denominado polariscópio, que, em sua operação, utiliza as propriedades da luz polarizada. Essas ondas são usadas para determinação do estado de tensão através do padrão de interferência luminosa ${ }^{7}$ formada por um sistema de iluminação, um par de polarizadores e uma estrutura para sustentar e estabilizar o modelo analisado ${ }^{8}$.

Para determinar os resultados qualitativos da ordem de franjas isocromáticas e isoclínicas, necessitou-se de um grande número de pontos e de medidas, além de tempo para sua obtenção e interpretação. Após a tomada fotográfica, as imagens deverão ser impressas, parâmetros deverão ser traçados e um mapa da ordem de franja deverá ser construído para a obtenção dos resultados.

Inicialmente, foram realizados testes experimentais em modelos-piloto, com a finalidade de permitir a correta investigação da metodologia e dos materiais a serem utilizados, definir o número de repetições necessárias, técnica de confecção desses modelos, técnica de leitura, calibração do pesquisador e obtenção de resultados confiáveis ${ }^{15}$.

Para a construção de um modelo fotoelástico ideal, foram seguidos alguns princípios básicos para que não ocorressem erros. A utilização de dentes multirradiculares em modelos fotoelásticos pode comprometer a interpretação dos resultados, devido à sobreposição de franjas que, possivelmente, irão ocorrer em função da proximidade entre as raízes ${ }^{4,6}$.

Evitou-se material resinoso com retorno lento em condição de estresse e que apresentasse tensão residual antes e depois da suspensão das forças aplicadas. Além disso, obrigatoriamente, esse deveria ter baixo módulo de elasticidade, alta constante óptica e resistência, ser de fácil manipulação e baixo custo ${ }^{15}$.

Ao surgir o interesse pela análise da mola $\mathrm{T}$ em modelo fotoelástico, e considerando-se que o estudo seria limitado aos movimentos iniciais do dente, optou-se pela análise de um padrão de ativação inicial (posição neutra), para, posteriormente, se analisar a mola T com ativação intermediária e, finalmente, em ativação máxima. Segundo Burstone e Koenig²,3, a ativação máxima da mola $\mathrm{T}$ seria de $6,0 \mathrm{~mm}$ e a posição neutra seria de $0,0 \mathrm{~mm}$. Outros autores consideram que a ativação máxima desse dispositivo seria de $5,0 \mathrm{~mm}$, sendo que em posição neutra ela apresentaria uma ativação de $2,0 \mathrm{~mm}^{14,20,21}$.

Em relação ao tipo de liga utilizada na confecção da mola T, optou-se pela de titânio-molibdênio, uma vez que, clinicamente, seria a mais indicada devido à magnitude de força ser menor ${ }^{24}$ quando comparada àquelas confeccionadas com fio de aço inoxidável ${ }^{19,22,23}$.

A mola $T$ centralizada no espaço interbraquetes apresenta valores semelhantes para o sistema de forças liberado entre os segmentos da unidade de ancoragem e a de retração ${ }^{10,17,20,21}$, resultantes da dobra de pré-ativação em "V" simétrico, provocando clinicamente movimentos dentários mais simétricos. 
$\mathrm{Na}$ análise dos gráficos, nota-se, tanto para a préativação de 30 graus como a de 45 graus, que: na base apical, pode-se observar que, em posição neutra, a distribuição das franjas fotoelásticas ocorreu simetricamente em ambas as pré-ativações. A diferença ocorrida foi na quantidade das franjas, que aumentou gradativamente conforme o aumento da ativação. Isso gerou, consequentemente, maior magnitude de força. Ao comparar a magnitude de força entra as duas pré-ativações (Gráf. 8 e Gráf. 17), pode-se afirmar que a maior magnitude foi observada na pré-ativação de 30 graus.

$\mathrm{O}$ posicionamento da mola $\mathrm{T}$ no espaço interbraquetes e a quantidade de ativação estão diretamente relacionados ao tipo de movimento gerado por esse dispositivo. Ao ativar a mola T em $5,0 \mathrm{~mm}$, a proporção $\mathrm{M} / \mathrm{F}$ é de 7,6 , permitindo movimento de inclinação controlada, pois seu centro de rotação estará posicionado mais para apical ${ }^{3}$. Após $1,0 \mathrm{~mm}$ de desativação, a proporção M/F será de 9,1 . Nessa, os dentes se movimentarão por translação. Se essa desativação continuar, o movimento dentário irá ocorrer por movimento radicular ${ }^{3}$ e, nessa hora, a mola deverá ser reativada para evitar contato entre as raízes dos dentes adjacentes às extrações dentárias.

Nesse estudo experimental fotoelástico, observou-se uma concentração maior de franjas fotoelásticas na região cérvico-mesial e nenhuma franja na região disto-apical na ativação máxima de ambas as molas. Conforme a desativação acontecia, essa ordem de franja diminuía na região cérvico-mesial e aumentava na região mesio-apical, até a ordem de franja alcançar maior concentração de energia na região mesio-apical e menor nas regiões cérvicomesial e disto-apical. Com essas características qualitativas, pode-se deduzir que, em ativação máxima, as molas promoveram tendência de movimento radicular na ativação de $0,0 \mathrm{~mm}$; movimento de corpo na ativação média; e, finalmente, na ativação máxima, movimento de inclinação controlada.

Nos gráficos 2, 6, 7, 15, 18 e 19 a ordem de franja apresenta-se inferior a 0,5. Algumas assimetrias, observadas nos gráficos 2, 5, 6, 7, 9, 15 , 18 e 19, demonstram valores insignificantes. É importante ressaltar que essas assimetrias podem ser resultantes de uma excentricidade no posicionamento da mola $\mathrm{T}$ ou diferença ocorrida no desenho final da mesma.

Também nota-se que o sistema de forças liberado, em todos os grupos de teste, mostrou-se simétrico para ambos os dentes (13 e 23). Os resultados são coerentes aos observados em testes realizados com ensaios mecânicos $3,11,19,20,21,23,24$, que mostramse significativamente semelhantes.

\section{CONSIDERAÇÕES FINAIS}

Utilizando o método experimental fotoelástico para análise qualitativa do sistema de forças liberado pela mola $\mathrm{T}$ centralizada e confeccionada com fio de TMA 0,017 " x 0,025 ", pode-se concluir que:

1. O estado de tensão em toda a superfície radicular da mola $\mathrm{T}$ com pré-ativação preconizada por Souza et al. ${ }^{20}$ mostrou-se discretamente maior quando comparado com a mola $\mathrm{T}$ com pré-ativação preconizada por Marcotte ${ }^{14}$.

2. Com ativação de $2,5 \mathrm{~mm}$, a ordem de franjas exibiu uma tendência de movimento de inclinação controlada.

3. A ordem de franjas mostrou-se semelhante na ativação de $2,5 \mathrm{~mm}$ para as pré-ativações de $30^{\circ}$ e de $45^{\circ}$.

4. Com ativação de $5,0 \mathrm{~mm}$, a concentração de energia, ou de força, mostrou-se claramente maior em ambas as pré-ativações. 


\title{
Qualitative photoelastic study of the force system produced by retraction T-springs with different preactivations
}

\begin{abstract}
Objective: Evaluate the force system produced by the T-spring used for space closure. Methods: By means of the experimental photoelastic method, we evaluated the T-spring —used for space closure-with two different preactivations on its apical portion, i.e., one with $30^{\circ}$ and one with $45^{\circ}$. The springs were fabricated with rectangular 0.017 $X 0.025$-in titanium-molybdenum alloy (TMA), centered in a $27.0 \mathrm{~mm}$ interbracket space and activated at $5.0 \mathrm{~mm}$ and $2.5 \mathrm{~mm}$, and in a neutral position. For more reliable results, tests were repeated on three photoelastic models duplicated and prepared by the same operator. To better understand the results, the fringes seen in the polariscope were photographed and analyzed qualitatively. Results: Through qualitative analysis of the fringe order in the photoelastic model it was noted that at the retraction and anchoring ends the T-spring with $30^{\circ}$ apical activation showed a slightly greater accumulation of energy relative to the force system that was generated.
\end{abstract}

Keywords: Closing of orthodontic space. T loop. Photoelastic study. Retraction.

\section{REFERÊNCIAS}

1. Articolo LC, Kusy K, Saunders CR, Kusy RP. Influence of ceramic and stainless steel brackets on the notching of archwires during clinical treatment. Eur J Orthod. 2000 Aug;22(4):409-25.

2. Burstone CJ. The segmented arch approach to space closure. Am J Orthod. 1982 Nov;82(5):361-78.

3. Burstone CJ, Koenig HA. Optimizing anterior and canine retraction. Am J Orthod. 1976 Jul:70(1):1-19.

4. Burstone CJ, Pryputniewicz RJ. Holographic determination of centers of rotation produced by orthodontic forces. Am J Orthod. 1980 Apr;77(4):396-409.

5. Chaconas SJ, Caputo AA, Davis JC. The effects of orthopedic forces on the craniofacial complex utilizing cervical and headgear appliance. Am J Orthod. 1976 May;69(5):527-39.

6. Chaconas SJ, Caputo AA, Miyashita K. Force distribution comparisons of various retraction archwires. Angle Orthod. 1989 May:59(1):25-30.

7. Dally JW, Rilley WF. Experimental stress analysis. New York: McGrall-Hill; 1965.

8. Glickman I, Roeber FW, Brion M, Pameijer JHN. Photoelastic analysis of internal stresses in the periodontium created by occlusal forces. J Periodontol. 1970 Jan;41(1):30-5.

9. Haraldson T. Photoelastic study of some biomechanical factors affecting the anchorage of osseointegrated implants in the jaw. Scand J Plast Reconstr Surg. 1980;14(3):209-14.

10. Hoenigl KD, Freudenthaler J, Marcotte MR, Bantleon HP. The centered T-loop: a new way of preactivation. Am J Orthod Dentofacial Orthop. 1995 Aug;108(2):149-53.

11. Kuhlberg AJ, Burstone CJ. T-loop position and anchorage control. Am J Orthod Dentofacial Orthop. 1997 Jul;112(1):12-8.

12. Kusy RP, Whitley JQ. Friction between different wire-bracket configurations and materials. Semin Orthod. 1997:3(3):166-77.

13. Lotti RS, Mazzieiro ET, Landre J Jr. A influência do posicionamento da alça T segmentada durante o movimento de retração inicial. Uma avaliação pelo método dos elementos finitos. Rev Dental Press Ortod Ortop Facial. 2006 maiojun;11(3):41-54

14. Marcotte MR. Biomecânica em Ortodontia. São Paulo: Ed. Santos; 1993.

15. Oliveira EJ. Material e técnica para análise fotoelástica plana da distribuição de tensões produzidas por implantes odontológicos. [dissertação]. Uberlândia (MG). Universidade Federal de Uberlândia; 2003.

16. Reitan K. Continuous bodily tooth movement and its histological significance. Acta Odontol Scand. 1947;7:115-44.
17. Shimizu RH. Fechamento de espaços após exodontias de primeiros pré-molares. [dissertação]. Araraquara (SP). Universidade Estadual Paulista; 1995.

18. Shimizu RH. Estudo dos sistemas de forças gerados pelas alças ortodônticas para fechamento de espaços. [tese]. Araraquara (SP). Universidade Estadual Paulista; 1999

19. Shimisu RH, Sakima T, Santos-Pinto A, Shimizu IA. Desempenho biomecânico da alça "T", construída com fio de aço inoxidável, durante o fechamento de espaços no tratamento ortodôntico. Rev Dental Press Ortod Ortop Facial. 2002 nov-dez; 7(6):49-61

20. Souza RS, Santos-Pinto A, Shimizu RI, Sakima MT, Gandini LG Jr. Avaliação do sistema de forças gerado pela alça T de retração, pré-ativada segundo o padrão UNESP-Araraquara. Rev Dental Press Ortod Ortop Facial. 2003 set-out;8(5):113-22.

21. Souza RS, Shimizu RI, Sakima MT, Santos-Pinto A, Gandinl LG Jr. Avaliação do sistema de forças gerado pela alça $T$ de retração pré-ativada segundo o padrão Marcotte. JBO: J Bras Ortod Ortop Facial. 2005;10(55):50-8.

22. Thiesen G, Rego MVNN, Menezes LM, Shimizu RH. Avaliação biomecânica de diferentes alças ortodônticas de fechamento de espaços confeccionadas com aço inoxidável. Rev Assoc Paul Especial Ortod Ortop Facial. 2004 abr-jun;2(2):77-92.

23. THiesen G, Rego MVN, Menezes LM. A pré-ativação de alças ortodônticas para fechamento de espaços e seu efeito no sistema de forças gerado. Ortodontia Gaúcha. 2004 jan-jun;8(1):42-59.

24. Thiesen G, Rego MVNN, Menezes LM, Shimizu RH. A utilização de diferentes configurações de molas T para obtenção de sistemas de forças otimizados. Rev Dental Press Ortod Ortop Facial. 2006 set-out;11(5):57-77.

25. Zak B. Photoelastiche analyse in der orthodontischen mechanik. Z Stomatol. 1935:33:22-37.

Enviado em: setembro de 2007

Revisado e aceito: novembro de 2008

Endereço para correspondência

Luiz Guilherme Martins Maia

Rua Terêncio Sampaio, 309

CEP: 49.025-700 - Aracaju / SE

E-mail: orthomaia2003@yahoo.com.br 